\title{
Environmental drivers of growth and predicted effects of climate change on a commercially important fish, Platycephalus laevigatus
}

\author{
Joshua Barrow $^{1, *}$, John Ford $^{1,2}$, Rob Day ${ }^{1}{ }$, John Morrongiello ${ }^{1}$ \\ ${ }^{1}$ School of BioSciences, University of Melbourne, Parkville 3010, Victoria, Australia \\ ${ }^{2}$ Mezo Research, 28 Freshwater Place, Southbank, Melbourne 3006, Victoria, Australia
}

\begin{abstract}
Human-driven climate change and habitat modification are negatively impacting coastal ecosystems and the species that reside within them. Uncovering how individuals of key species respond to environmental influences is crucial for effective and responsive coastal resource and fisheries management. Here, using an otolith based analysis, we recreated the growth history of rock flathead Platycephalus laevigatus from Corner Inlet, Victoria, Australia, over a $32 \mathrm{yr}$ timeframe and related growth variation to changes in key environmental variables. Growth increased with higher temperatures during the fish growing season (December-May) and also increased with higher freshwater flow during the period important for seagrass growth (JulyFebruary). We hypothesise that fish are responding to enhanced productivity in the seagrass food web, driven by increased nutrient input from freshwater flows. Fish also appear to be responding to higher temperatures via a direct physiological pathway. We then predicted fish growth under 3 plausible climate change scenarios. Growth is predicted to increase across all our projections, because any predicted decrease in river flow will likely be offset by rapid predicted increases in temperature. Our results highlight the value of understanding the drivers of long-term growth variation in harvested fishes as this allows for the prediction of future productivity under a range of environmental and management scenarios.
\end{abstract}

KEY WORDS: Climate change $\cdot$ Coastal ecosystems - Ecosystem resilience $\cdot$ Fisheries productivity Fish growth $\cdot$ Variable growth $\cdot$ Otolith $\cdot$ Sclerochronology

\section{INTRODUCTION}

Coastal areas are dynamic and complex environments that support valuable fisheries around the world (FAO 2016). Occurring at the interface of land and sea, they are naturally affected by both terrestrial and marine processes that together play a fundamental role in driving variation in abiotic conditions (Alongi 1998). Coastal waters are, however, heavily affected by human activity (Halpern et al. 2008) and climate change (Harley et al. 2006). The growth information naturally archived in fish otoliths provides a unique opportunity to recreate multi-decadal time series in regions where monitoring data does not exist

${ }^{*}$ Corresponding author: j.barrow@student.unimelb.edu.au

${ }^{\S}$ Advance View was available online September 5, 2017
(Morrongiello et al. 2012, Poloczanska et al. 2016). This valuable longer-term perspective is vital to understanding and managing the impacts of natural and anthropogenic change on fisheries productivity.

Habitat forming species such as seagrass play a fundamental role in underpinning the productivity of coastal fisheries (Butler \& Jernakoff 1999, Ellison et al. 2005). For example, seagrass provides protection and resources for newly settled larvae and juvenile fishes (Jenkins et al. 1997, Ford et al. 2010), as well as feeding and spawning opportunities for adults (Klumpp \& Nichols 1983). The health and productivity of seagrass itself is driven by both terrestrial and marine processes that are increasingly being modi-

() The authors 2018. Open Access under Creative Commons by Attribution Licence. Use, distribution and reproduction are unrestricted. Authors and original publication must be credited. 
fied by humans (Orth et al. 2006). Terrestrial runoff, marine currents, and wind-driven mixing provide nutrients that fertilise seagrass beds. However, in urbanised and agricultural catchments, nutrient loads can exceed natural levels and result in phytoplankton blooms and excessive algal growth that reduce light penetration or smother seagrass (Thomsen et al. 2012). Likewise, catchment erosion increases water turbidity which can also retard seagrass growth. Globally, seagrasses are declining at an accelerating rate (Waycott et al. 2009) with consequent detrimental impacts to many species that depend on them.

Coastal fishery productivity is also directly affected by freshwater inflows. For example, Morrongiello et al. (2014) found that recruitment success and growth rate of an estuarine fish was strongly related to high freshwater flows during the spawning season and during the growing year. These results suggest that flows play an important role in providing both a spawning cue and favourable conditions for larval survival and juvenile and adult growth. Increased recruitment success and somatic growth subsequently impacts the biomass of adults, and therefore fishery productivity (Bardos et al. 2006, Whitten et al. 2013). While increased nutrients often positively influence ecosystem productivity, excessive nutrient inputs can promote harmful algal blooms (McComb et al. 1995). Further, sediment and phytoplanktonrelated increases in turbidity can negatively affect the foraging success of visual predators (Abrahams \& Kattenfeld 1997, Sohel et al. 2017). Reduced prey encounter rates and food acquisition can subsequently affect individual growth and fitness. River flow can therefore affect the primary productivity of the foundation species, and drive the abundances and reproductive success of all trophic levels, including key fisheries species.

Fishes have physiological tolerances that allow them to live within a specific range of variation in environmental factors (Barton et al. 2002). Changes in environmental conditions, such as temperature, beyond this range can influence abundances and distributions, and can be stressful or even fatal to fish (Roessig et al. 2004). In many species, a slight temperature increase may be initially beneficial as it results in increased energy and therefore increased growth (Takasuka \& Aoki 2006). However, if temperature exceeds the optimal range for a particular species, it can be deleterious to growth (Wang \& Overgaard 2007). In coastal environments many fishes may also be completely dependent on specific habitat, so their persistence in that ecosystem will depend on the response of that habitat to fluctuations in temperature. Rainfall, nutrient upwelling and temperature will all vary with wind patterns and ocean circulation, so average wind direction and oceanic indices can also be important predictors of these 3 key environmental parameters affecting fish growth.

The effects of environmental change on coastal ecosystem productivity, and in particular the growth rates and production of commercial resources in coastal ecosystems, have seldom been examined at longer time-scales, probably due to the lack of good long-term monitoring in most such systems. Similarly, the importance of juvenile growth rates for fisheries dynamics is increasingly understood (Cowan et al. 2000, Whitten et al. 2013), but the factors controlling it have seldom been investigated at the time scales relevant to both fishery management and predicting future climate change effects. A novel way to overcome the lack of longer term monitoring is to use fish otoliths as records of growth rates (Thresher et al. 2007, Black 2009, Matta et al. 2010, Morrongiello \& Thresher 2015), and then relate these to available environmental data records.

This study investigates the influence of 4 environmental factors - freshwater flows, temperature, wind, and the Southern Oscillation Index (SOI) - on the growth of the commercially important fish, rock flathead Platycephalus laevigatus, in Corner Inlet, Victoria, Australia. We explore the environmental drivers of growth variation in this species using mixed effects models to analyse otolith samples from 1982 to 2014. We recreate a 32 yr growth biochronology and partition growth into its intrinsic and extrinsic components (Weisberg et al. 2010 Morrongiello \& Thresher 2015). We then use these models to predict fish growth under a range of plausible future climate scenarios.

We expect that the growth of flathead will reflect a complex integration of different physical processes and causal pathways (Fig. 1). We predict that freshwater flow can affect growth via 2 distinct and opposing mechanisms: increased flow during the period July-February will provide critical nutrients for seagrass and thus result in habitat expansion, which in turn will promote flathead growth. Conversely, higher flows during the period December-May (the fish growing period) will increase turbidity and limit the efficacy of feeding, as flathead are ambush predators. We expect that increased temperatures during the growing season will promote fish growth via a direct physiological pathway (this population is approximately in the middle of its range, so should be favoured by warming), or via an indirect promotion 


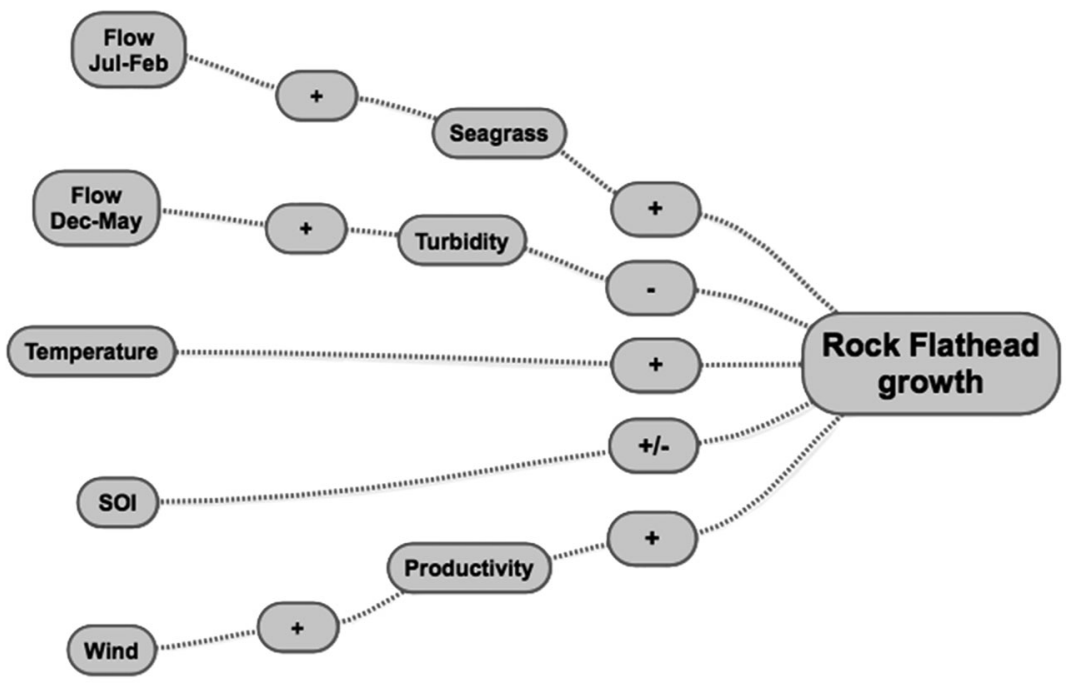

Fig. 1. Conceptual model of the predicted effects of environmental factors on rock flathead Platycephalus laevigatus growth. Plus (+) and minus (-) signs indicate that there could be a positive or negative influence of the environmental factor on the subsequent effect or habitat. For example, higher river flow in July-February could increase seagrass cover, and subsequently increase rock flathead growth

of primary productivity that has a positive cascading effect through the food web. This effect would be consistent with a previous growth study on rock flathead from Western Australia (Coulson et al. 2014). We hypothesise that zonal westerly winds will increase nutrient upwelling and thus promote system productivity, whilst we also expect that fish growth will be positively correlated with positive SOI values (La Niña events), which affects local rainfall and thus stream flows.

\section{MATERIALS AND METHODS}

\section{Study site}

Corner Inlet Marine and Coastal Park $\left(38^{\circ} 45^{\prime} 57^{\prime \prime} \mathrm{S}, 146^{\circ} 20^{\prime} 21^{\prime \prime} \mathrm{E}\right)$ is a large embayment (18500 ha) in Victoria, approximately $180 \mathrm{~km}$ southeast of Melbourne (Fig. 2). The inlet comprises extensive shallow sand and mudflats at $<2 \mathrm{~m}$ depth fragmented by deeper tidal channels. Subtidal seagrass beds are abundant on the shallow areas and composed mainly of Posidonia australis and Zostera nigracaulis. These seagrass beds are vital habitat for many fish and invertebrate species within Corner Inlet, including a number of commercially important fish species
(Kemp et al. 2013). The main growth window for both seagrass species is the late winter to early summer period (July-February), when epiphyte growth is depressed due to low water temperatures (Ford et al. 2016). Seagrass cover in Corner Inlet has declined $23 \%$ in the past $48 \mathrm{yr}$, at a rate of $0.5 \mathrm{~km}^{2} \mathrm{yr}^{-1}$ (Ford 2014, Ford et al. 2016). This seagrass decline, attributed to algal blooms and turbidity, may have affected the productivity of the ecosystem and its reliant species.

\section{Study species}

Rock flathead Platycephalus laevigatus is a seagrass-associated fish inhabiting shallow water throughout southern Australia (Koopman et al. 2004). The Corner Inlet population is approximately in the middle of this species' distribution, and contains both spawning and recruited individuals; however, linkages with other populations are currently unknown (Koopman et al. 2004, Kemp et al.

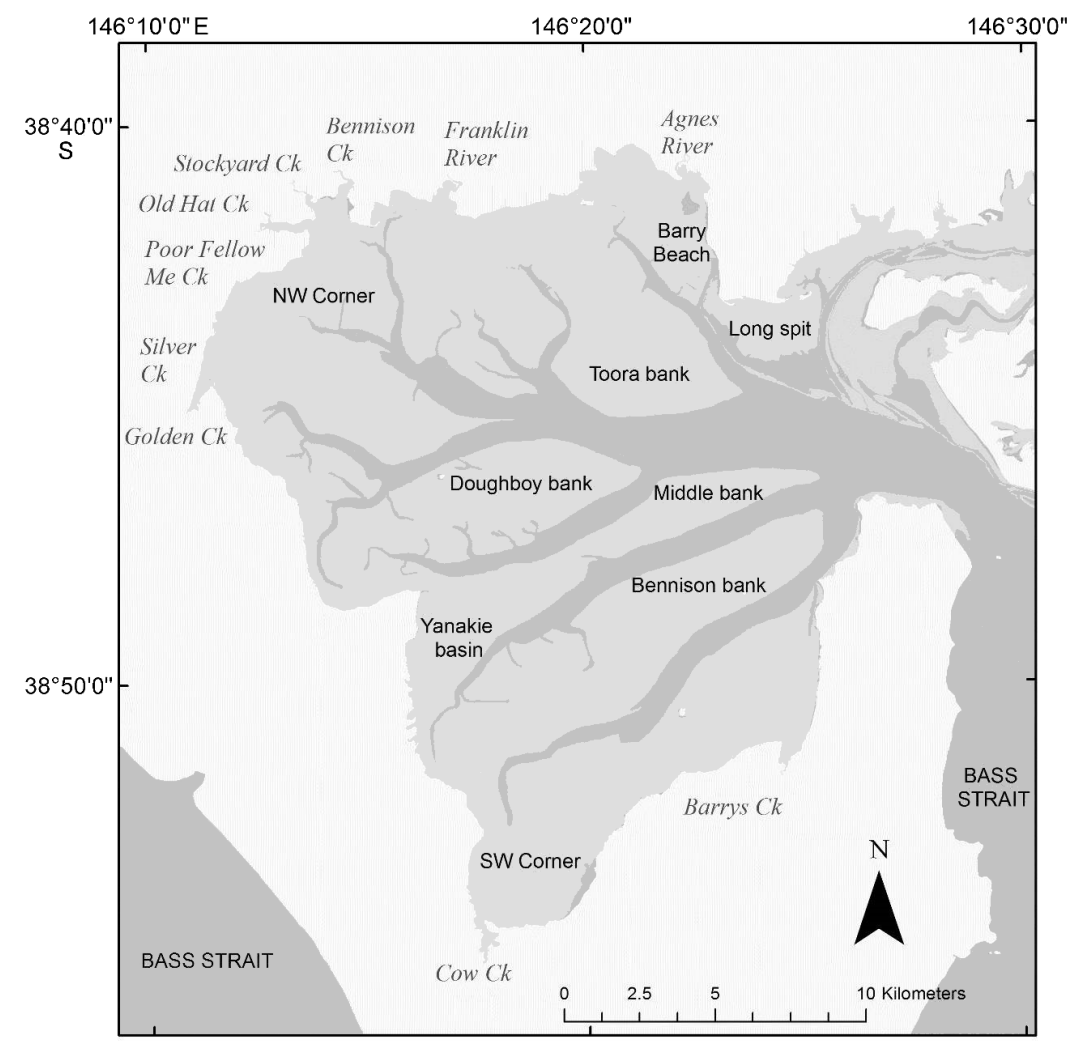

Fig. 2. Corner Inlet, Victoria, Australia (from Ford et al. 2016) 


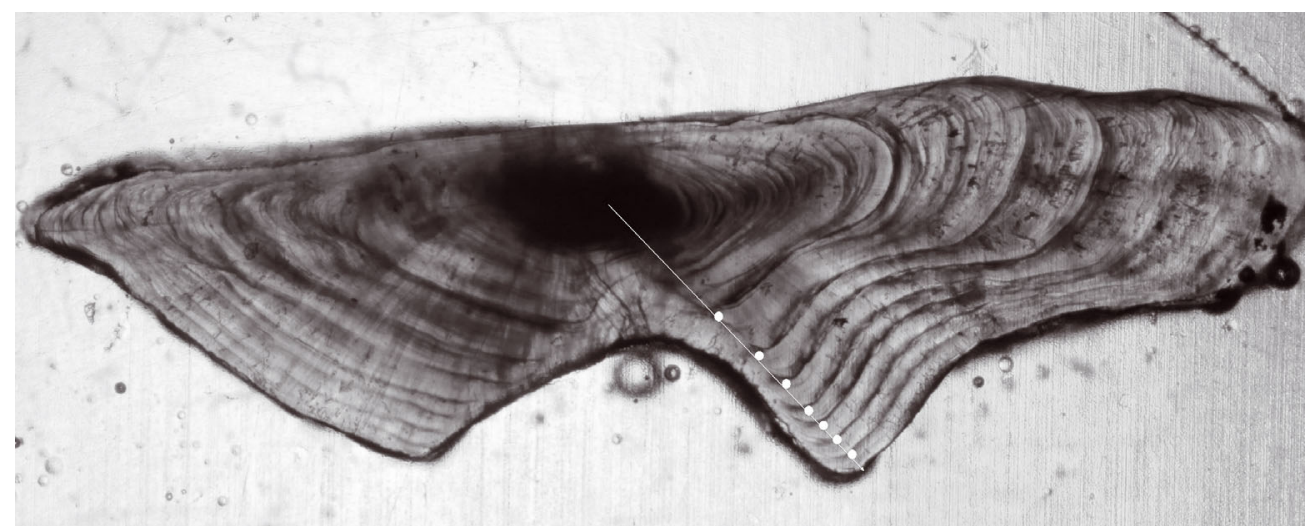

Fig. 3. Sectioned Platycephalus laevigatus otolith with 7 opaque zones, taken with transmitted light. The white line identifies the axis along which the age of the otolith was estimated, and the circles identify where measurements between opaque zones were taken

2013). Newly settled $P$. laevigatus spend the first part of their life on bare sand flats before moving into the seagrass beds as older juveniles and remaining there as adults (Jenkins et al. 1993). In Corner Inlet, rock flathead constitutes approximately $23 \%$ by weight of the total fishery, and is one of the most valuable species along with King George whiting Sillaginodes punctatus and southern calamari Sepioteuthis australis (Kemp et al. 2013). Rock flathead, King George whiting and southern calamari together contribute over AU\$1.6 million of the total 'off the boat' value of the fishery, and are also important recreationally targeted species (Department of Primary Industries 2012).

\section{Sample collection and estimation of age and growth}

Otoliths from 526 fish were collected from the commercial fishery over the period 1994-2014. One otolith from each fish was embedded in clear epoxy resin (EpoFix) in embedding moulds $(14 \times 5 \times 6 \mathrm{~mm})$. Using a low speed diamond saw (South Bay Technology Model 650) we cut a transverse section $(\sim 0.3 \mathrm{~mm})$ through the core of the otolith (previously marked with pencil under a microscope). The sections were ground and polished (using a South Bay Technology Model 920 lapping and polishing machine), then mounted on a microscope slide. Digital images of each section were captured using a Canon EOS 60D digital camera attached to a compound microscope at $\times 40$ magnification.

Coulson et al. (2014) used marginal increment analysis to show that a single opaque zone is laid down annually in otoliths of $P$. laevigatus throughout its life. Therefore, opaque zones can be used to determine the age of fish from this species. Using the same method, Koopman et al. (2004) established that opaque zones are laid down in December in Corner
Inlet rock flathead. We counted the opaque zones on the dorsal side of the otolith to determine the age of each fish, taking into consideration the date that the fish were caught and the birth date of the species. Despite individuals being found in spawning condition in most months throughout the year, the main spawning period of $P$. laevigatus in Victoria is between September and February (Koopman et al. 2004). Therefore an arbitrary birthdate of December 1 was chosen to correspond with the middle of the spawning period and the period of new increment formation.

We used Image Pro Plus software (v.6.3, Mediacybernetics) to measure growth increments on the sectioned otoliths. Measurements were taken of the distances between the outer edges of each opaque zone, to determine the width of each consecutive growth increment (Fig. 3). We also measured the distance between the otolith core and the periphery (outermost edge of the otolith). We used this measurement to compare otolith size and total fish length, ensuring that otolith growth is an appropriate proxy for fish somatic growth (Fig. S1 in the Supplement at www.int-res.com/articles/suppl/m598p201_supp. pdf). Measurements were restricted to increments after the second growth ring because the location of the first growth ring can reflect 8-14 mo of growth depending on when an individual was spawned.

\section{Statistical analyses}

We investigated the sources of variation in annual growth of rock flathead (increment width in $\mathrm{mm}$ ) using a mixed effects modelling framework. Models contained different combinations of fixed intrinsic predictors (within-individual), fixed extrinsic predictors (environmental), and their interactions. Each increment width was treated as a separate response sample, which resulted in 2145 total increment meas- 
Table 1. Descriptions of intrinsic (within-individual), extrinsic (environmental) and random factors used in rock flathead Platycephalus laevigatus growth analysis, with ranges and means of measured values (where applicable)

\begin{tabular}{|c|c|c|c|}
\hline Parameter & Description & Range & Mean \\
\hline \multicolumn{4}{|c|}{ Intrinsic factors } \\
\hline AOG & Age at which the year of growth occurred & $2-17 \mathrm{yr}$ & $4.5 \mathrm{yr}$ \\
\hline AAC & Age at which the fish was captured & $2-17 \mathrm{yr}$ & $6.9 \mathrm{yr}$ \\
\hline Sex & Male or female & & \\
\hline \multicolumn{4}{|c|}{ Extrinsic factors } \\
\hline Temperature & $\begin{array}{l}\text { Average maximum temperature during the main } \\
\text { growth period (Dec-May) }\end{array}$ & $20.9-25.3^{\circ} \mathrm{C}$ & $23.2^{\circ} \mathrm{C}$ \\
\hline \multirow[t]{4}{*}{ Flow } & River flow from the Agnes and Franklin rivers & & \\
\hline & $\begin{array}{lr}\text { during seagrass growth (Jul-Feb) and flathead } & \text { July-Feb highest 10\%: } \\
\text { growth (Dec-May) of the previous year. } & \text { July-Feb median: }\end{array}$ & $\begin{array}{c}100.8-1912.3 \mathrm{Ml} \\
18.8-125.1 \mathrm{Ml}\end{array}$ & $\begin{array}{c}646.9 \mathrm{Ml} \\
74.8 \mathrm{Ml}\end{array}$ \\
\hline & Calculated as mean of highest $10 \%$ of flows Dec-May highest $10 \%$ : & $44.7-1173.5 \mathrm{Ml}$ & $341.94 \mathrm{Ml}$ \\
\hline & per year, and median flow. & 8.1-29.7 Ml & $29.7 \mathrm{Ml}$ \\
\hline Wind & $\begin{array}{l}\text { Zonal westerly wind index, based on direction } \\
\text { and strength of winds }\end{array}$ & $-70.4-465.4$ & 184.7 \\
\hline SOI & Monthly Southern Oscillation Index & $-1.2-19.7$ & -1.2 \\
\hline \multicolumn{4}{|c|}{ Random factors } \\
\hline 1IYear & Year that the increment was formed & & \\
\hline 1IFishID & Unique code which identifies each fish & & \\
\hline AOGIX & Random age slope for X (FishID and Year random intercepts) & & \\
\hline
\end{tabular}

urements. The issue of non-independence of increments from the same fish was dealt with in the model structure as described below.

\section{Intrinsic predictors}

Fixed intrinsic predictors were sex, age of the fish at the time the growth increment was formed (AOG), and age at capture (AAC) (Table 1). Age at capture was included in the data to test for any bias associated with age selectivity in the samples (Morrongiello et al. 2012). We introduced a random intercept for FishID to induce a correlation among increment measurements and allow each fish to have higher or lower growth than the model's intercept, and to account for non-independence of the response data (Morrongiello \& Thresher 2015). Similarly, increments formed by different fish in a given year are also non-independent as the sampled fish were exposed to the same environmental conditions. We included a random intercept for Year to induce a correlation among increments at this level. We also investigated whether including a random age slope for FishID (AOGIFishID) and Year (AOGlYear), would improve the fit of the model (Table 2). These random slopes allow for individual-specific differences in the growth-age relationship, and year-dependent differences in age-specific growth.

\section{Extrinsic predictors}

We developed 4 environmental variables to test our hypotheses about the drivers of variation in fish growth (Fig. 1). These fixed extrinsic factors included the temperature in that year (Temperature), nutrient input from freshwater flows in the corresponding year and the months leading up to that year (Flow), wind strength and direction in that year (Wind), and the southern oscillation index for that year (SOI) (Table 1; Figs. S2 \& S3 in the Supplement). Mean maximum temperature was available from a nearby weather station for the period between December and May, from 1982-2014 (Bureau of Meteorology 2017). Air temperature was used as a proxy for sea temperature as the

Table 2. Model selection results for random effects structures of rock flathead Platycephalus laevigatus annual growth. Models included the maximal fixed effect structure of AOG $\times$ Sex. Columns are: degrees of freedom (df), difference in Akaike's information criterion (AIC) value ( $\triangle \mathrm{AIC}$ ), AIC weight, and restricted log likelihood (LL)

\begin{tabular}{|lccccc|}
\hline Random effects models & df & $\Delta$ AIC & $\begin{array}{c}\text { AIC } \\
\text { weight }\end{array}$ & LL \\
\hline AOGIFishID + AOGIYear & 11 & 0 & 1 & 753.49 \\
AOGIFishID + 1IYear & 9 & 82.16 & 0 & 710.39 \\
1/FishID + 1IYear & 9 & 127.23 & 0 & 687.86 \\
1IFishID + AOGIYear & 7 & 199.76 & 0 & 649.58 \\
\hline
\end{tabular}


latter data were not available (correlation between air temperature and sea surface temperature in nearby Port Phillip Bay; $r=0.71$ ) (NOAA 2015). Daily temperature data were then averaged over the fish growing season (December-May).

Daily river flows (Ml) were available for the Franklin River and Agnes River, the main tributaries into Corner Inlet (Department of Environment, Land, Water and Planning 2015). Higher freshwater flows deliver nutrients to estuaries and coastal waters used by seagrasses, encouraging frond rejuvenation. Seagrass growth typically occurs when the temperature begins to warm in spring (Ford et al. 2016). The mean of the top $10 \%$ of river flows per year (representing the quantity of water during large flow events), and the median flows (representing annual variation in average flow conditions) were calculated for 2 time periods: from July when the seagrass has declined over the winter until the end of February when the seagrass is typically rejuvenated, and also over the main fish growing period (December-May). We used the mean of the top $10 \%$ as an arbitrary high percentage of flows instead of a Q10 value (flow which is exceeded $10 \%$ of the time), as it was a more accurate representation of the extent of large flow events that were not as well captured by the Q10 value.

Wind can have an important influence on ocean current patterns off the Victorian coast, and therefore the ocean input into bays and inlets along the southern coast (Hamer et al. 2010). The methods for developing a zonal westerly wind (ZWW) index are outlined in Hamer et al. (2010). In this study, we used average ZWW from the main fish growing period (December-May) as the environmental indicator.

The Southern Oscillation Index (SOI) is a measure of El Niño Southern Oscillation events that represents regional climate variability by quantifying El Niño and La Niña events in the Pacific Ocean (Bureau of Meteorology 2017). Negative values (El Niño events) are typically associated with warmer sea surface temperatures and drier regional conditions. Positive values (La Niña events) are typically associated with cooler sea surface temperatures and higher probability of rainfall (Bureau of Meteorology 2017).

\section{Model comparisons}

To satisfy model assumptions, we log-transformed the growth (increment width), AOG and AAC data. The predictor variables were centered to facilitate model convergence and interpretation of interaction and polynomial terms (Morrongiello \& Thresher
2015). Firstly, we created a base model including AOG and AAC and explored different random effect structures (using restricted maximum likelihood estimation, REML). We then compared models with and without AAC using maximum likelihood (ML). Competing random effect and then intrinsic effect models were then ranked using Akaike's information criterion corrected for small sample size (AICc), and the difference between the best model (lowest AICc) and each other model ( $\triangle \mathrm{AIC}$ ) (Morrongiello \& Thresher 2015). The best fitting of these models would become the base model for introducing the fixed extrinsic factors (Morrongiello et al. 2014).

Building on this base model, we fitted a series of models with different combinations of extrinsic factors and their interactions with AOG. These interaction terms allow for age-dependent growth responses to environmental variables. Competing models were fit using ML and ranked using AICC and $\triangle \mathrm{AICC}$ values. The best model was then refitted with REML to produce unbiased parameter estimates (Zuur et al. 2009). In addition, we calculated conditional (all factors) $\mathrm{R}^{2}$ values for the best models. This $\mathrm{R}^{2}$ value describes the proportion of variation in growth described by all factors in the model (Nakagawa \& Schielzeth 2013). Models were fit using the lme4 package (Bates et al. 2015) in the program $\mathrm{R}$ (v. 0.98.977) (R Core Team 2014). Models were compared using the AICcmodavg package (Mazerolle 2015), and predictions and confidence intervals generated using the arm and Effects packages (Fox 2003, Gelman \& Hill 2006).

\section{Climate change scenarios}

We predicted rock flathead growth, using the best fitting model under 3 possible climate change scenarios: 2030, 2055/70 (high emissions), 2055/70 (low emissions) (Stocker 2014). Projections were estimated as a change relative to the baseline period 1986-2005. We used the median values of predicted temperature change for Gippsland, Victoria, for 2030, 2070 (high emissions) and 2070 (low emissions). The ranges exclude the upper and lower $10 \%$ of results (CSIRO \& Bureau of Meteorology 2015). Changes to river flow were estimated using the mean of our flow parameter values (top $10 \%$ July-February) from between 1986-2005 as a baseline. We used the flow estimation model for South Gippsland, Victoria, from Jones \& Durack (2005) to estimate the median percentage change to mean flows for 2030 and 2055. We used the third lowest and third highest 
values of 10 climate model predictions for 2030 and 2055 to indicate the range of values (Jones \& Durack 2005). We converted the percentage change in flows predicted by the model to estimate actual changes to flow relative to our 1986-2005 baseline flow.

\section{RESULTS}

\section{Intrinsic and random factors}

The increment widths on a total of 526 otoliths were measured, resulting in 2145 individual increment measurements, dating from 1982 to 2014. The best intrinsic effect model included an AOG $\times$ Sex interaction, with random AOG slopes for Year and FishID (Table 2). Growth declined with age, with females having faster growth later in life than males (>5 yr old) (Fig. 4). We plotted the Year random intercepts from the best model to visualise temporal patterns in growth (Fig. 5). Rock flathead displayed a high variation in growth over time. There was a period of strong growth from 1995 to 2001, then a poor growth period between 2002 and 2006. 2010 was a strong growth year, but it was immediately followed by a poor growing year in 2011 .

\section{Extrinsic factors}

The best extrinsic effects model included additive effects of temperature in the fish growing seasons (December-May) and high flow during the seagrass growing season (highest 10\% flows in July-February) (Table 3). This model had an AIC weight of 0.41 , compared to weights of $0.11,0.06$ and 0.05 of the next best fitting models (Table 4). The best fitting model reflects that rock flathead growth increased as freshwater inflows increased in the months that the seagrass rejuvenates with rising tem-

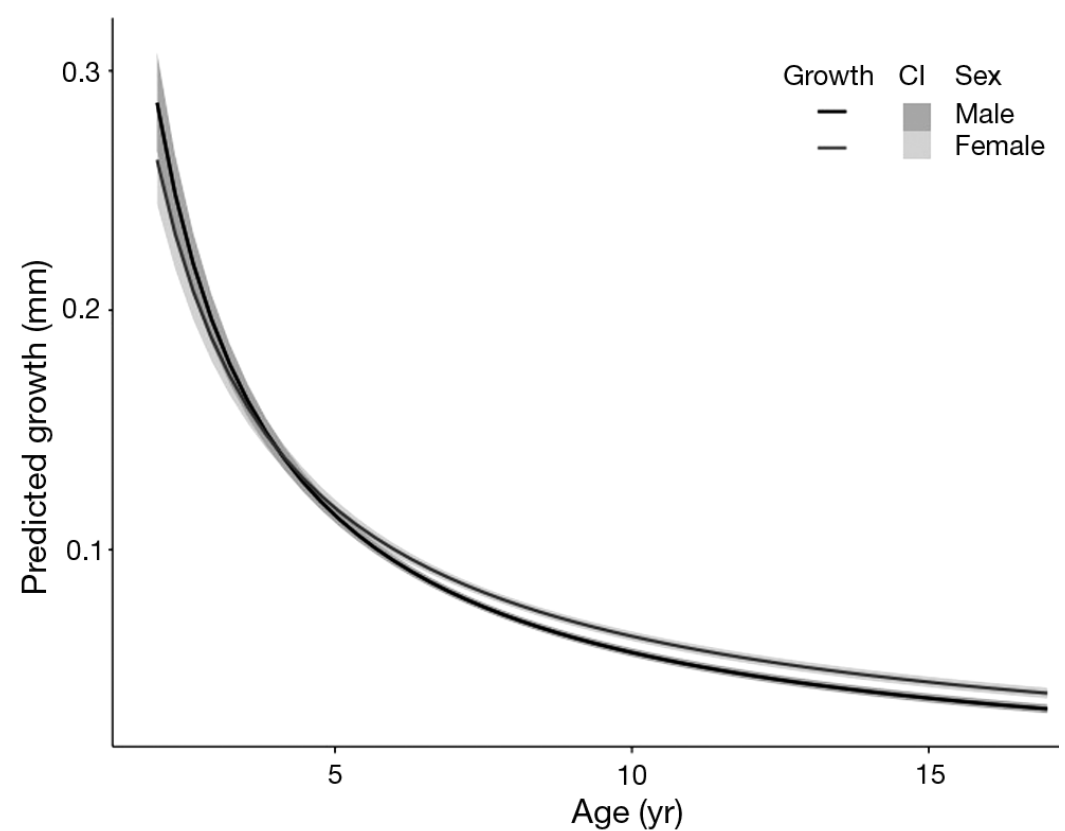

Fig. 4. Predicted growth of male (dark grey) and female (light grey) rock flathead Platycephalus laevigatus otolith increments $(\mathrm{mm})$ at each age of growth (years). Shaded areas are $95 \%$ confidence intervals

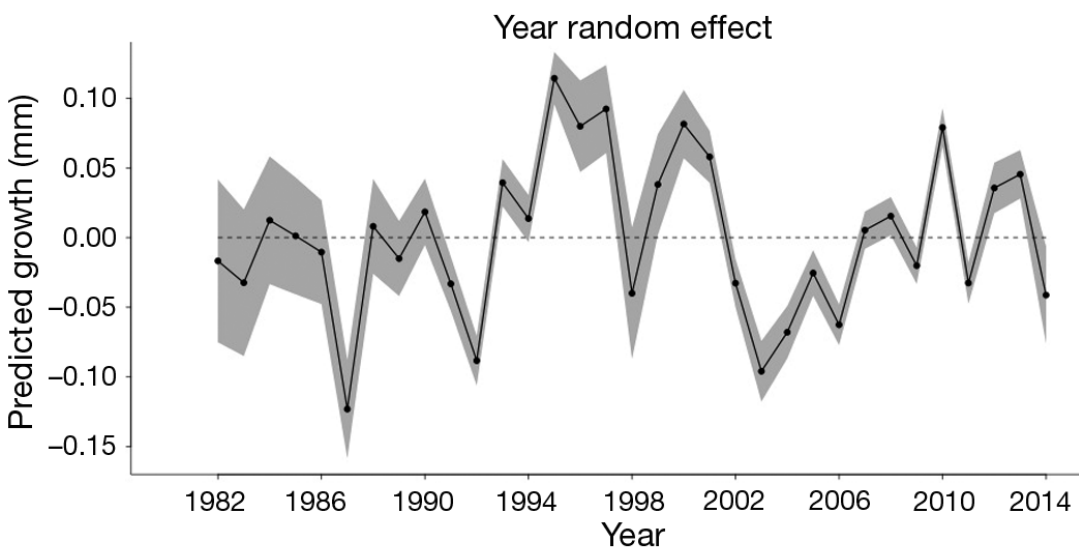

Fig. 5. Variation in predicted annual growth (accounting for intrinsic effects) of rock flathead Platycephalus laevigatus, represented by year random effect

Table 3. Parameter estimates (with SE), 95\% confidence intervals and test statistic $(t)$ from the best-fit model of rock flathead Platycephalus laevigatus annual growth

\begin{tabular}{|lccrrr|}
\hline Parameter & Estimate & SE & $5 \%$ CI & $95 \%$ CI & $t$ \\
\hline Intrinsic factors & & & & & \\
Intercept & -2.672 & 0.0129 & -2.694 & -2.651 & -206.28 \\
Age & -1.004 & 0.0286 & -1.051 & -0.958 & $\mathbf{- 3 5 . 0 7}$ \\
Sex (F) & 0.0889 & 0.0127 & 0.068 & 0.110 & $\mathbf{6 . 9 9}$ \\
Age $\times$ Sex & 0.124 & 0.0225 & 0.086 & 0.163 & $\mathbf{5 . 5 1}$ \\
Extrinsic factors & & & & & \\
Temperature & 0.0298 & 0.0111 & 0.011 & 0.049 & $\mathbf{2 . 6 8}$ \\
Flow (Highest 10\% Jul-Feb) & 0.00008 & 0.00003 & 0.00003 & 0.0001 & $\mathbf{2 . 8 3}$ \\
\hline
\end{tabular}


Table 4. Overall best fitting models of rock flathead Platycephalus laevigatus annual growth including intrinsic, random and extrinsic factors, after a comparison of AICc values. Columns are degrees of freedom (df), difference in AIC value ( $\triangle \mathrm{AIC})$, AIC weight, maximised log likelihood (LL) and the $\mathrm{R}^{2}$ value

\begin{tabular}{|lcccccc|}
\hline Model's extrinsic factors & df & $\Delta$ AIC & $\begin{array}{c}\text { AIC } \\
\text { weight }\end{array}$ & LL & $\mathrm{R}^{2}$ \\
\hline $\begin{array}{l}\text { Temperature + Flow } \\
\text { (highest 10\% Jul-Feb) }\end{array}$ & 13 & 0 & 0.41 & 770.39 & 0.938 \\
Flow (highest 10\% Jul-Feb) + Wind & 13 & 2.70 & 0.11 & 769.04 & 0.938 \\
Wind & 12 & 3.89 & 0.06 & 767.44 & 0.938 \\
Flow (highest 10\% Jul-Feb) & 12 & 4.07 & 0.05 & 767.34 & 0.938 \\
\hline
\end{tabular}

peratures (July-February) (Fig. 6). Rock flathead growth also increased in warmer fish growing seasons (December-May) (Fig. 7). Temperature and river flow were negatively correlated $(r=-0.63)$, yet growth appears to be enhanced by increases in both factors, which suggests that any correlation has not obscured the influence of either factor.

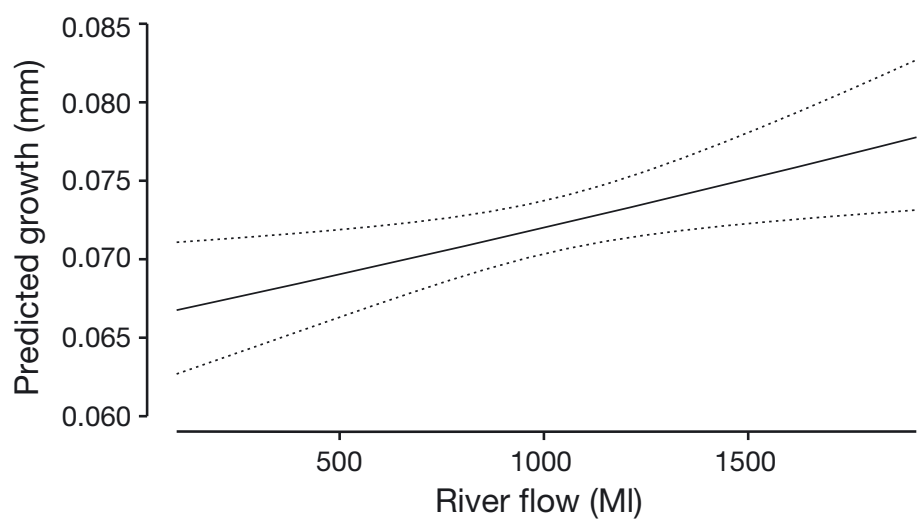

Fig. 6. Predicted otolith incremental growth (mm) and confidence intervals of rock flathead Platycephalus laevigatus with freshwater river flows

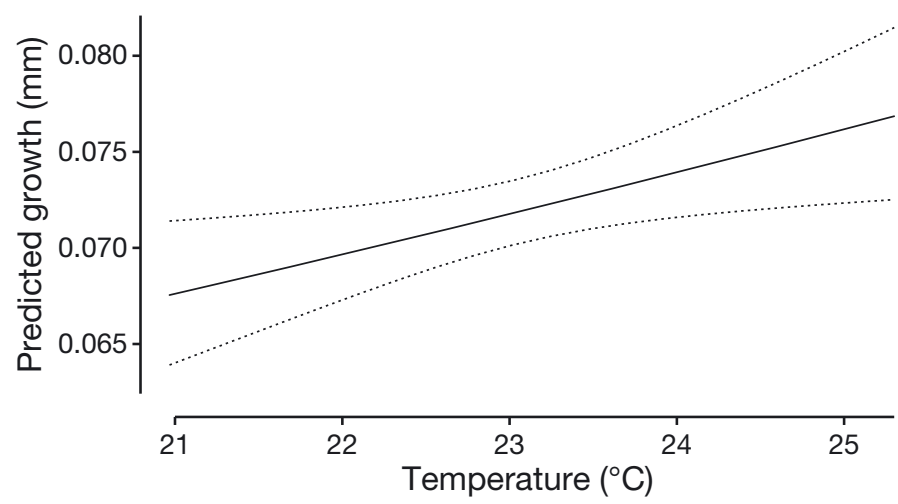

Fig. 7. Predicted otolith incremental growth (mm) and confidence intervals of rock flathead Platycephalus laevigatus in increasing temperatures $\left({ }^{\circ} \mathrm{C}\right)$

\section{Climate change scenarios}

We predict that mean annual growth of $2 \mathrm{yr}$ old rock flathead in 2030 will increase by $2.46 \%$ as temperature increases and river flow decreases. In 2070 under a low emissions scenario, we predict that growth will increase by $3.58 \%$. In 2070 under a high emissions scenario, we predict that growth will increase by $6.67 \%$ (Fig. 8).

\section{DISCUSSION}

Annual growth of rock flathead in Corner Inlet was significantly influenced by environmental factors. Growth was higher in periods following larger river flows and likely represents a response to nutrient-rich river flow stimulating productivity through the seagrass food web. High temperatures during summer and autumn also increased the growth of all individuals in the population. Our model explicitly incorporates both intrinsic and extrinsic sources of growth variation and allows managers to identify whether changes in fish stocks are likely to be related to environmental or fishing factors.

\section{Intrinsic factors}

Age (AOG) explained a substantial amount of the variation in growth and reflects the commonly observed pattern of fish growth decreasing when individuals get older. The significant interaction between age and sex was also expected. There was no effect of sex on growth in young individuals $(<5 \mathrm{yr})$, but in older fish ( $>5 \mathrm{yr})$ females exhibited significantly larger growth than males. This is consistent with previous studies on P. laevigatus and tiger flathead P. richardsoni (Koopman et al. 2004, Morrongiello \& Thresher 2015). It is beneficial for female fish to grow faster and larger than male fish so that they can accommodate more eggs during the spawning period (Koopman et al. 2004). In most fish the growth of males and their growth efficiency declines more than females after maturity, perhaps because they are more active in finding and displaying to mates (Henderson et al. 2003, Pauly 2010). These behaviours have been observed in other related species in the Platycephalidae family (Shinomiya et al. 2003). 

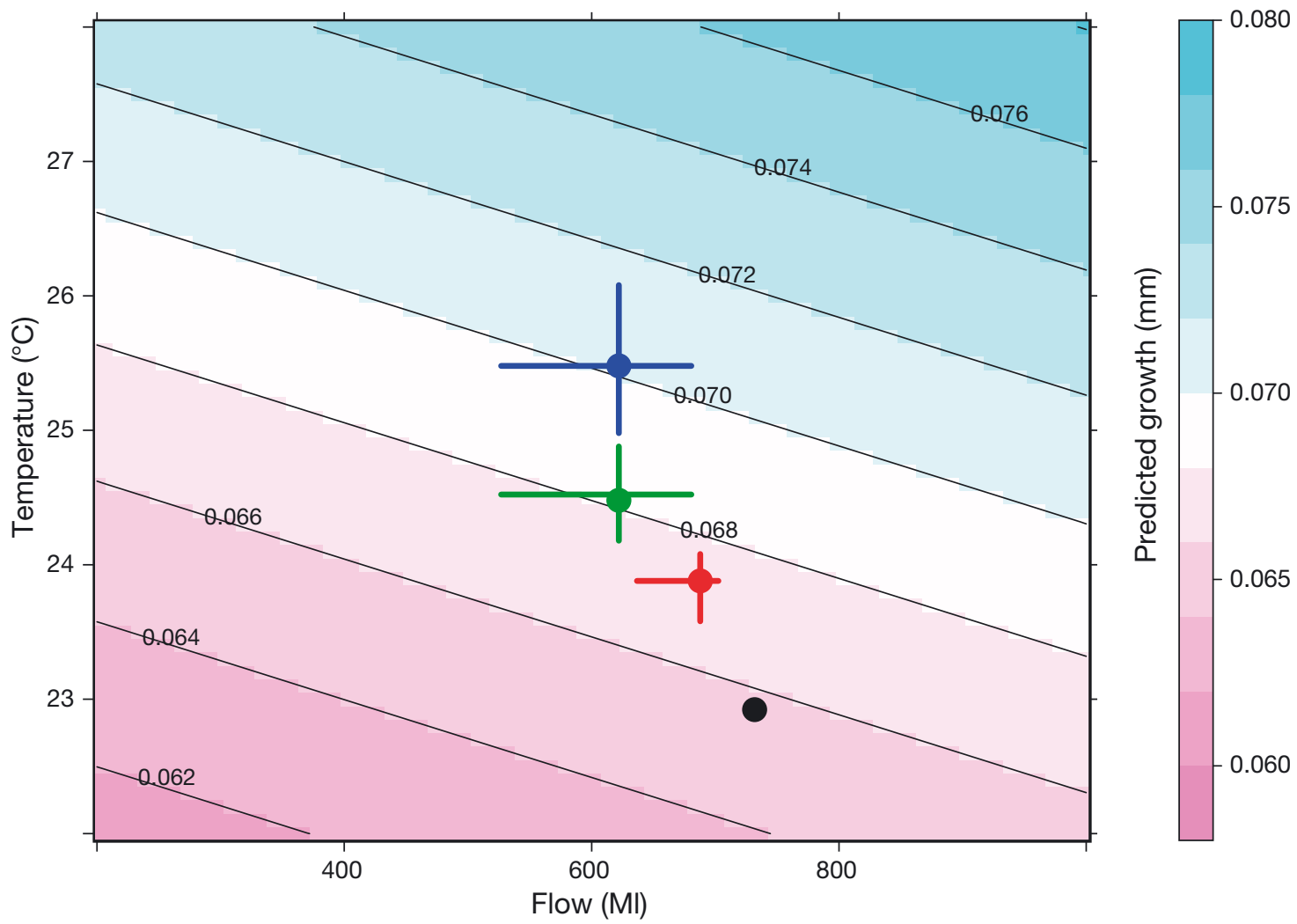

Fig. 8. Predicted otolith incremental growth ( $\mathrm{mm})$ and confidence intervals of rock flathead Platycephalus laevigatus in current temperatures and productivity (1986-2005) and under 3 climate change scenarios: current baseline (black), 2030 (red), $2070+$ low emissions (green), $2070+$ high emissions (blue)

\section{Environmental influences on fish growth}

Rock flathead growth was positively influenced by increased river flow which we hypothesise stimulates productivity in the seagrass ecosystem. It is well understood that estuarine and coastal ecosystems are more productive than areas distant from the coast (Whitfield 1996). This productivity is often driven by the availability of nutrients from nutrientrich river flows (Caddy \& Bakun 1994) and subsequently cascades up the food web to predators such as rock flathead (Edgar \& Shaw 1995). Corner Inlet is a seagrass dominated environment. This seagrass predominantly grows during spring and summer, so increased nutrient input from the rivers at this time may especially enhance productivity of the seagrass ecosystem and increase abundances of prey. Excessive nutrient input from river inflows, however, is suspected to lead to algal blooms and thus seagrass decline (Ford et al. 2016). In spite of this, we found no evidence of a negative impact of higher flow levels on rock flathead growth, and thus a humpshaped relation of growth to flow. One possibility is that the fishery catches were focused on areas that retained good seagrass habitat. The impacts of high nutrients on the health of seagrass and consequently on species inhabiting the seagrass deserve further investigation.

Increased temperatures during the main growth period (December-May) resulted in increased fish growth. As fish are ectothermic, their metabolic rate varies with the external water temperature. Within the range of temperatures that fish are exposed to, species will have an optimal range in which their metabolism is enhanced (Christie \& Regier 1988). Increases in temperature (within the optimal range) can result in a direct increase in growth, through allocation of enhanced energy (Fry 1971). Our results are consistent with those from a previous growth study on rock flathead (Coulson et al. 2014). As Corner Inlet is in the middle of rock flathead's distribution, we expect that warming water will promote fish growth. Similar patterns have been observed in a multi-population analysis of the related tiger flathead P. richarsoni (Morrongiello \& Thresher 2015). Inreased temperatures can also improve the productivity of the seagrass ecosystem (Masini et al. 1995), and thus indirectly promote rock flathead growth via 
increases in food. It is possible that increases in rock flathead growth with warming water represents a combination of both direct metabolic and indirect food web mechanisms.

\section{Climate change scenarios}

We predict that rock flathead growth rates will increase in the future. Warmer temperatures associated with climate change may be slightly offset by a simultaneous decrease in flow, though in general the magnitude of the temperature effect is greater and would be expected to have a stronger impact on growth (Fig. 8) (Jones \& Durack 2005, CSIRO \& Bureau of Meteorology 2015). While the future productivity of the fishery may be enhanced by increased fish growth, it is important to remember that rock flathead are reliant on the seagrass ecosystem for both habitat and nutrition. Future seagrass declines that occur due to changes in flow or even independently of climate (Ford et al. 2016), will likely have strong impact on fish growth. Further study is required to understand the cumulative impacts that anthropogenic and climate driven environmental change have on the seagrass ecosystem.

Whilst we think our predictions of enhanced growth with warming are robust, they do not account for changed frequency and intensity of extreme events (e.g. marine heatwaves and unpredictable flooding events; Hobday et al. 2016) that can impact biological systems (Wernberg et al. 2013). Predicted changes in mean temperature for 2030 and 2070 (low emissions) are both within the observed temperature range of the study, while the predicted temperature for 2070 (high emissions) exceeds the highest yearly mean temperature by $0.82^{\circ} \mathrm{C}$. Nonetheless, daily temperatures often exceed this value, so that we are confident that predicted temperatures will not exceed physiological tolerances for rock flathead. The values for predicted changes in river flow, and therefore nutrient input into Corner Inlet, are well within the observed range of river flows. Rock flathead have therefore already been exposed to all of the predicted temperatures and river flow scenarios.

\section{Implications for the fishery and ecosystem management}

Our study indicates that freshwater flows that enhance the productivity of the seagrass ecosystem stimulate the growth of rock flathead. This informa- tion is important for fisheries and ecosystem managers because it provides clear empirical evidence for the need to appropriately manage catchment processes and water extraction to ensure fisheries production is maintained. Such an ecosystem-based management approach is increasingly being employed to ensure the ongoing sustainable management of fisheries worldwide. Future work needs to focus on understanding the drivers of poor water quality, seagrass declines and how seagrass-inhabiting species are impacted, so that practical strategies can be put in place to promote recovery (e.g. managing the terrestrial impacts on the content of freshwater flows, seagrass transplantation). We also need to understand the mechanisms driving growth and successful recruitment of other commercially important species in Corner Inlet, to make informed decisions that will benefit all major species within the fishery.

Acknowledgements. All collection of specimens and field survey methods were carried out with the permission of the Department of Environment, Land, Water and Planning National Parks Act 1975 Research Permit (permit no. 10007406) and the Department of Environment and Primary Industries Fisheries Act 1995 Permit (permit no. RP1135). We thank Fisheries Victoria for their help supplying us with historical samples. We thank Gary Cripps and Ray Dunstone for boating support and providing some recent samples. We also thank Neville Clarke, Brett Cripps, Wayne Cripps, and Lachie and Alice from Foster Seafood for providing additional recent samples for this project.

\section{LITERATURE CITED}

Abrahams MV, Kattenfeld MG (1997) The role of turbidity as a constraint on predator-prey interactions in aquatic environments. Behav Ecol Sociobiol 40:169-174

Alongi DM (1998) Coastal ecosystems processes. CRC Press, Boca Raton, FL

Bardos DC, Day RW, Lawson NT, Linacre NA (2006) Dynamical response to fishing varies with compensatory mechanism: an abalone population model. Ecol Model 192: 523-542

Barton BA, Morgan JD, Vijayan MM (2002) Physiological and condition related indicators of environmental stress in fish. In: Adams SM (ed) Biological indicators of ecosystem stress. American Fisheries Society, Bethesda, MD, p 111-148

Bates D, Maechler M, Bolker B, Walker S (2015) Fitting linear mixed-effects models using lme4. J Stat Softw 67: $1-48$

Black BA (2009) Climate-driven synchrony across tree, bivalve, and rockfish growth-increment chronologies of the northeast Pacific. Mar Ecol Prog Ser 378:37-46

Bureau of Meteorology (2017) Climate data online. Bureau of Meteorology. www.bom.gov.au/climate/data/ (accessed 25 May 2017)

Butler A, Jernakoff P (1999) Seagrass in Australia. Strategic 
review and development of an R\&D plan. CSIRO Publishing, Collingwood

Caddy JF, Bakun A (1994) A tentative classification of coastal marine ecosystems based on dominant processes of nutrient supply. Ocean Coast Manage 23:201-211

Christie GC, Regier HA (1988) Measures of optimal thermal habitat and their relationship to yields for four commercial fish species. Can J Fish Aquat Sci 45:301-314

Coulson PG, Black BA, Potter IC, Hall NG (2014) Sclerochronological studies reveal that patterns of otolith growth of adults of two co-occurring species of Platycephalidae are synchronized by water temperature variations. Mar Biol 161:383-393

* Cowan JH Jr, Rose KA, De Vries DR (2000) Is densitydependent growth of young-of-the-year fishes a question of critical weight? Rev Fish Biol Fish 10:61-89

CSIRO and Bureau of Meteorology (2015) Climate change in Australia: information for Australia's Natural Resource Management Regions. Technical Report, CSIRO and Bureau of Meteorology. https://www.environment. gov.au/system/files/pages/61971ba0-0847-4fef-846e36d6b706a7a5/files/corner-inlet-fishery-corner-inletnooramunga-fishery-assessment.pdf

* Department of Environment, Land, Water and Planning (2015) Water Measurement Information System, Department of Environment, Land, Water and Planning, Melbourne. http://data.water.vic.gov.au/monitoring.htm (accessed 1 August 2015)

Department of Primary Industries (2012) Fisheries Victoria commercial fish production information bulletin 2012 . Fisheries Victoria, Queenscliff

Edgar GJ, Shaw C (1995) The production and trophic ecology of shallow-water fish assemblages in southern Australia II. Diets of fishes and trophic relationships between fishes and benthos at Western Port, Victoria. J Exp Mar Biol Ecol 194:83-106

Ellison AM, Bank MS, Clinton BD, Colburn EA and others (2005) Loss of foundation species: consequences for the structure and dynamics of forested ecosystems. Front Ecol Environ 3:479-486

FAO (2016) The state of world fisheries and aquaculture 2016. FAO, Rome

Ford JR (2014) A review of the chemical toxicant threats to seagrass in Corner Inlettoria. Report to the West Gippsland Catchment Management Authority, as part of Fisheries Research Development Corporation Project 13/021, Melbourne

Ford JR, Williams RJ, Fowler AM, Cox DR, Suthers IM (2010) Identifying critical estuarine seagrass habitat for settlement of coastally spawned fish. Mar Ecol Prog Ser 408:181-193

Ford JR, Barclay K, Day RW (2016) Using local knowledge to understand and manage ecosystem-related decline in fisheries productivity. Fisheries Research and Development Corporation Final Project Report, Melbourne. http:// frdc.com.au/research/Final_reports/2013-021-DLD.pdf

Fox J (2003) Effect displays in R for generalised linear models. J Stat Softw 8:1-27

Fry FEJ (1971) 1-The effect of environmental factors on the physiology of fish. Fish Physiol 6:1-98

Gelman A, Hill J (2006) Data analysis using regression and multilevel/hierarchical models. Cambridge University Press, New York, NY

Halpern BS, Walbridge S, Selkoe KA, Kappel CV and others (2008) A global map of human impact on marine ecosys- tems. Science 319:948-952

Hamer P, Jenkins G, Kemp J (2010) Linking key environmental and life history indicators for monitoring and assessment of bay and inlet fisheries in Victoria. Fisheries Victoria Research Report Series No. 44, Melbourne

Harley CD, Randall Hughes A, Hultgren KM, Miner BG and others (2006) The impacts of climate change in coastal marine systems. Ecol Lett 9:228-241

* Henderson BA, Collins N, Morgan GE, Vaillancourt A (2003) Sexual size dimorphism of walleye (Stizostedion vitreum vitreum). Can J Fish Aquat Sci 60:1345-1352

* Hobday AJ, Alexander LV, Perkins SE, Smale DA and others (2016) A hierarchical approach to defining marine heatwaves. Prog Oceanogr 141:227-238

Jenkins GP, Hammond LS, Watson GF (1993) Patterns of utilisation of seagrass (Heterozostera) dominated habitats as nursery areas by commercially important fish. Victorian Institute of Marine Sciences, Report No. 19. Queenscliff

Jenkins GP, May HMA, Wheatley MJ, Holloway MG (1997) Comparison of fish assemblages associated with seagrass and adjacent unvegetated habitats of Port Phillip Bay and Corner Inlet, Victoria, Australia, with emphasis on commercial species. Estuar Coast Shelf Sci 44:569-588

Jones RN, Durack PJ (2005) Estimating the impacts of climate change on Victoria's runoff using a hydrological sensitivity model. CSIRO Atmospheric Research, Melbourne

Kemp J, Brown L, Bruce T, Bridge N, Conron S (2013) Corner Inlet and Nooramunga Fishery Assessment 2012. Fisheries Victoria Assessment Report Series No. 68. Department of Primary Industries, Queenscliff

Klumpp DW, Nichols PD (1983) A study of food chains in seagrass communities II. Food of the rock flathead, Platycephalus laevigatus Cuvier, a major predator in a Posidonia australis seagrass bed. Mar Freshw Res 34: 745-754

Koopman M, Morison AK, Troynikov VS (2004) Population dynamics and assessment of sand and rock flathead in Victorian waters. FRDC Report 2000/120. Department of Primary Industries, Queenscliff

Masini RJ, Cary JL, Simpson CJ, McComb AJ (1995) Effects of light and temperature on the photosynthesis of temperate meadow-forming seagrasses in Western Australia. Aquat Bot 49:239-254

*Matta ME, Black BA, Wilderbuer TK (2010) Climate-driven synchrony in otolith growth-increment chronologies for three Bering Sea flatfish species. Mar Ecol Prog Ser 413: $137-145$

* Mazerolle MJ (2015) AICcmodavg: Model selection and multimodel inference based on (Q)AIC(c). R package version 2.0-3. https://cran.r-project.org/web/packages/ AICcmodavg/AICcmodavg.pdf

McComb AJ, Atkins RP, Birch PB, Gordon DM, Lukatelich RJ (1995) The Peel-Harvey estuarine system, Western Australia. In: McComb AJ (ed) Eutrophic shallow estuaries and lagoons. CRC Press, London, p 5-17

Morrongiello JR, Thresher RE (2015) A statistical framework to explore ontogenetic growth variation among individuals and populations: a marine fish example. Ecol Monogr 85:93-115

*Morrongiello JR, Thresher RE, Smith DC (2012) Aquatic biochronologies and climate change. Nat Clim Chang 2: 849-857

* Morrongiello JR, Walsh CT, Gray CA, Stocks JR, Crook DA 
(2014) Environmental change drives long term recruitment and growth variation in an estuarine fish. Glob Change Biol 20:1844-1860

Nakagawa S, Schielzeth H (2013) A general and simple method for obtaining $\mathrm{R}^{2}$ from generalized linear mixed effects models. Methods Ecol Evol 4:133-142

NOAA (2015) NOAA high resolution SST data. NOAA/ OAT/ESRL PSD, Boulder, CO. http://www.esrl.noaa. gov/psd/

Orth RJ, Carruthers TJ, Dennison WC, Duarte CM and others (2006) A global crisis for seagrass ecosystems. Bioscience 56:987-996

Pauly D (2010) Gasping fish and panting squids: oxygen, temperature and the growth of water-breathing animals. In: Kinne O (ed) Excellence in ecology, Book 22. International Ecology Institute, Oldendorf/Luhe

* Poloczanska ES, Burrows MT, Brown CJ, García Molinos J and others (2016) Responses of marine organisms to climate change across oceans. Front Mar Sci 3:62

$\mathrm{R}$ Core Team (2014) R: A language and environment for statistical computing. R Foundation for Statistical Computing, Vienna

Roessig JM, Woodley CM, Cech JJ Jr, Hansen LJ (2004) Effects of global climate change on marine and estuarine fishes and fisheries. Rev Fish Biol Fish 14:251-275

Shinomiya A, Yamada M, Sunobe T (2003) Mating system and protandrous sex change in the lizard flathead, Inegocia japonica (Platycephalidae). Ichthyol Res 50: 383-386

Sohel S, Mattila J, Lindström K (2017) Effects of turbidity on prey choice of three-spined stickleback Gasterosteus aculeatus. Mar Ecol Prog Ser 566:159-167

Stocker T (ed) (2014) Climate change 2013: the physical science basis: Working Group I contribution to the Fifth

Editorial responsibility: Stylianos Somarakis, Heraklion, Greece assessment report of the Intergovernmental Panel on Climate Change. Cambridge University Press, Cambridge

Takasuka A, Aoki I (2006) Environmental determinants of growth rates for larval Japanese anchovy Engraulis japonicus in different waters. Fish Oceanogr 15:139-149

* Thomsen MS, Wernberg T, Engelen AH, Tuya F and others (2012) A meta-analysis of seaweed impacts on seagrasses: generalities and knowledge gaps. PLOS ONE 7 : e28595

* Thresher RE, Koslow JA, Morison AK, Smith DC (2007) Depth-mediated reversal of the effects of climate change on long-term growth rates of exploited marine fish. Proc Natl Acad Sci USA 104:7461-7465

Wang T, Overgaard J (2007) The heartbreak of adapting to global warming. Science 315:49-50

* Waycott M, Duarte CM, Carruthers TJ, Orth RJ and others (2009) Accelerating loss of seagrasses across the globe threatens coastal ecosystems. Proc Natl Acad Sci USA 106:12377-12381

Weisberg S, Spangler G, Richmond LS (2010) Mixed effects models for fish growth. Can J Fish Aquat Sci 67:269-277

* Wernberg T, Smale DA, Tuya F, Thomsen MS and others (2013) An extreme climatic event alters marine ecosystem structure in a global biodiversity hotspot. Nat Clim Chang 3:78-82

Whitfield AK (1996) Fishes and the environmental status of South African estuaries. Fish Manag Ecol 3:45-57

*Whitten AR, Klaer NL, Tuck GN, Day RW (2013) Accounting for cohort-specific variable growth in fisheries stock assessments: a case study from south-eastern Australia. Fish Res 142:27-36

Zuur AF, Ieno EN, Walker NJ, Saveliev AA, Smith GM (2009) Mixed effects models and extensions in ecology with R. Springer, New York, NY

Submitted: March 17, 2017; Accepted: June 21, 2017

Proofs received from author(s): August 25, 2017 